$$
\operatorname{CONF}-950476--11
$$

UCRL-JC-119427

PREPRINT

\title{
The X-Ray Laser as a Tool for Imaging Plasmas
}

\author{
S. B. Libby, L. B. Da Silva, T. W. Barbee, Jr., R. Cauble, \\ P. Celliers, R. A. London, D. L. Matthews, S. Mrowka, \\ J. C. Moreno, D. Ress, J. E. Trebes, A. S. Wan and F. Weber
}

This paper was prepared for submittal to the 12th International Conference on Laser Interaction and Related Plasma Phenomena

Osaka, Japan

April 24-28, 1995

July 1995

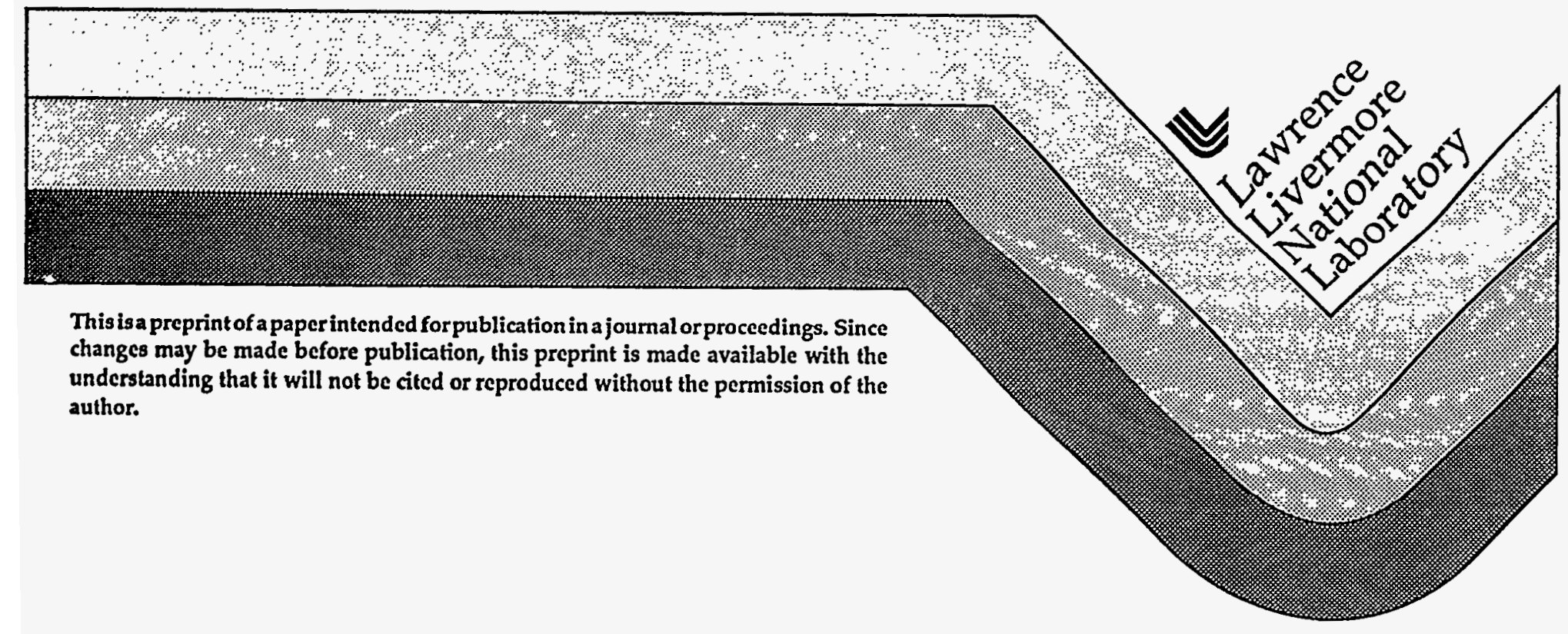




\section{DISCLAIMER}

This report was prepared as an account of work sponsored by an agency of the United States Government. Neither the United States Government nor any agency thereof, nor any of their employees, make any warranty, express or implied, or assumes any legal liability or responsibility for the accuracy, completeness, or usefulness of any information, apparatus, product, or process disclosed, or represents that its use would not infringe privately owned rights. Reference herein to any specific commercial product, process, or service by trade name, trademark, manufacturer, or otherwise does not necessarily constitute or imply its endorsement, recommendation, or favoring by the United States Government or any agency thereof. The views and opinions of authors expressed herein do not necessarily state or reflect those of the United States Government or any agency thereof. 


\section{DISCLAIMER}

Portions of this document may be illegible in electronic image products. Images are produced from the best available original document. 


\title{
The X-Ray Laser as a Tool for Imaging Plasmas
}

\author{
S. B. Libby, L. B. Da Silva, T. W. Barbee, Jr., R. Cauble, P. \\ Celliers, R. A. London, D. L. Matthews, S. Mrowka, J. C. \\ Moreno, D. Ress, J. E. Trebes, A. S. Wan, and F. Weber \\ Lawrence Livermore National Laboratory \\ University of Califomia \\ Livermore, California 94550 \\ USA
}

\begin{abstract}
The $\mathrm{x}$-ray laser is now being used at LLNL as a tool for measuring the behaviors of hot dense plasmas. In particular, we have used the $155 \AA$ yttrium laser to study transient plasmas by both radiography and moiré deflectometry. These techniques have been used to probe long scale length plasmas at electron densities exceeding $10^{22} \mathrm{~cm}^{-3}$. Recent advances in multilayer technology have made it possible to directly image ion densities in directly driven thin foils to an accuracy of $1-2 \mu \mathrm{m}$. In addition, we have constructed an $X$-ray laser Mach-Zehnder interferometer using multilayer beamsplitters. This interferometer yields direct 2D projections of electron densities in plasmas with micron spatial resolution. In addition, this interferometer can be used to measure spectral line shapes to high accuracy. Among the subject plasmas under study are laser irradiated planar targets, gold hohlraums, and $x$ ray lasers themselves.
\end{abstract}

$\mathrm{X}$-ray lasing has been demonstrated in laboratory plasmas at wavelengths ranging from 350 to $35 \AA(1,2)$. These lasers work by electron collision and recombination pumping. They have a high peak brightness that is equivalent to a $4 \pi$ blackbody radiator at a effective Planckian temperature of about $1 \mathrm{GeV}$. The laser line width is about $\Delta \omega / \omega$ $\sim 10^{-4}$ and the available pulse lengths range from about $1 \mathrm{~ns}$ to $50 \mathrm{ps}$. At Nova, these x-ray lasers are produced by line focused $10^{14} \mathrm{~W} / \mathrm{cm}^{2}$ irradiation (for yttrium lasing) of either a thin foil or a slab about $3 \mathrm{~cm}$ long. Typically, $\mathrm{x}$-ray lasers have a spatial mode structure that corresponds to an incoherent source of diameter of about $300 \mu \mathrm{m}$ propagated through the gain length of the laser $(3-4 \mathrm{~cm})$ and through an outgoing aperture also about $300 \mu \mathrm{m}$. Estimating the transverse coherence length via $L_{c} \sim \lambda / \theta$, where $\theta$ is the divergence of the laser, yields about $10^{4}$ Fresnel zones over the outgoing aperture.

The high brightness of the $\mathrm{x}$-ray laser makes it well suited to the problem of imaging targets that are themselves bright in the soft $x$-ray region $(3,4,5)$. Indeed, the main purpose of our recent work on $\mathrm{x}$-ray lasers is the development of an effective imaging tool for long scale 
length, high density plasmas of interest in ICF and general high energy density physics research. The high brightness also makes the laser ideal for use with multilayer mirrors and beam-splitters which can further aid in exploiting the coherence of the laser for imaging.

The relatively short wavelength of the laser allows us to probe dense $\left(>10^{21} / \mathrm{cc}\right)$, long scale length plasmas without problems due to refraction and absorption. In the past, refraction and absorption have made it difficult to image plasmas with densities exceeding $10^{21} / \mathrm{cc}(6,7$, 8). Since the index of refraction of in a plasma goes like $n \approx 1-n_{f} / 2 n_{\text {Cr }}$ with the critical density $n_{\mathrm{cr}} \sim 1.1 \times 10^{21} \lambda-2 / \mathrm{cc}$ (with $\lambda$ in $\mu \mathrm{m}$ ), the effects of refraction are significantly reduced by using a short wavelength probe. Furthermore, the short laser pulses available $(-50-350 \mathrm{ps})$ make it possible to freeze even rather rapid plasma evolution. Taken together, these features have allowed us to set up various soft $x$-ray imaging systems that can yield $2 \mathrm{D}$ images of the subject plasmas with up to $1-2 \mu \mathrm{m}$ resolution in an picture containing over 1 million pixels.

The neon-like yttrium $x$-ray laser is appropriate for our imaging applications because it has high energy $(\sim 8 \mathrm{~mJ})$ and is nearly monochromatic, with most of the energy appearing at $155 \AA$ which happens to be at a lucky overlap of two strong lines, the $\mathrm{J}=2$ to $\mathrm{J}=1$ and the $\mathrm{J}=0$ to $\mathrm{J}=1$ lines. This wavelength is also suited for the use of existing high reflectivity multilayer mirror technology. In particular, multilayer mirrors with $60 \%$ efficiency are available at this wavelength (9).

We have used the yttrium $x$-ray laser to probe ablation plasmas by three methods. They are simple radiography, moiré deflectometry, and Mach-Zehnder interferometry. These three methods exploit the spatial and temporal coherence of the $x$-ray laser to ever increasing degrees. One may compare the effective imaging brightness of each of these three methods to a $300 \mathrm{eV}$ blackbody backlighter. Taking into account the divergence, line width, and intensity of the laser, the relative brightnesses are respectively $\sim 15, \sim 10^{5}$ and $\sim 10^{7}$.

In the case of the use of the laser as a backlighter for radiography, the brightness ratio of 15 comes from comparing the laser illumination to that obtainable from the $300 \mathrm{eV}$ blackbody backlighter with the largest practical light gathering mirror. The radiography method yields a 2D shadow graph proportional to the line integral of the opacity to $155 \AA$ light through the sample (3). In many cases, such as that of high $\mathrm{Z}$ plasma, using this result to obtain the actual ion density of the ablation plasma is difficult because it requires delicate ionization balance and opacity modeling.

Moiré deflectometry measures electron density gradients through the deflections of a moiré mask pattern superimposed just before the detector on the basic radiography setup. The moire mask pattern is made by two superimposed striped gratings, where one is rotated relative to the other by a small angle $\theta$. The deflections of the moire mask pattern go like $\Delta \mathrm{X} \sim \vartheta \mathrm{d} / \sin (\theta)$, where $\vartheta \sim \partial \partial \mathrm{y}\left(\int \mathrm{nds}\right.$.). This method exploits the 
spatial coherence of the laser to some degree, in that it requires a match between the geometry of the moire pattern and the CCD detector array that is set by the spatial coherence of the laser. Thus this method is potentially more efficient than a blackbody backlighter by a factor of $\sim 1 / \theta^{2}$. For a detailed discussion of work on moire deflectometry, the reader should consult the paper by Ress et. al. (4) Though the moire method doesn't depend on knowing the opacity of the subject plasma, it is only sensitive to the gradient in the electron density. This gradient can be small in some plasmas of interest. Thus we are led to consider xuv interferometry as a method for determining absolute electron densities and thereby also ion densities.

In xuv interferometry a direct measurement of the index of refraction and thus $n_{e}$ is made by dividing the $x$-ray laser beam into a probe beam that passes through the subject plasma and a reference beam that propagates in vacuum and then recombining them to measure the relative phase shift $\delta \phi$. We have done this in a skewed Mach-Zehnder arrangement shown in figure 1 (5).

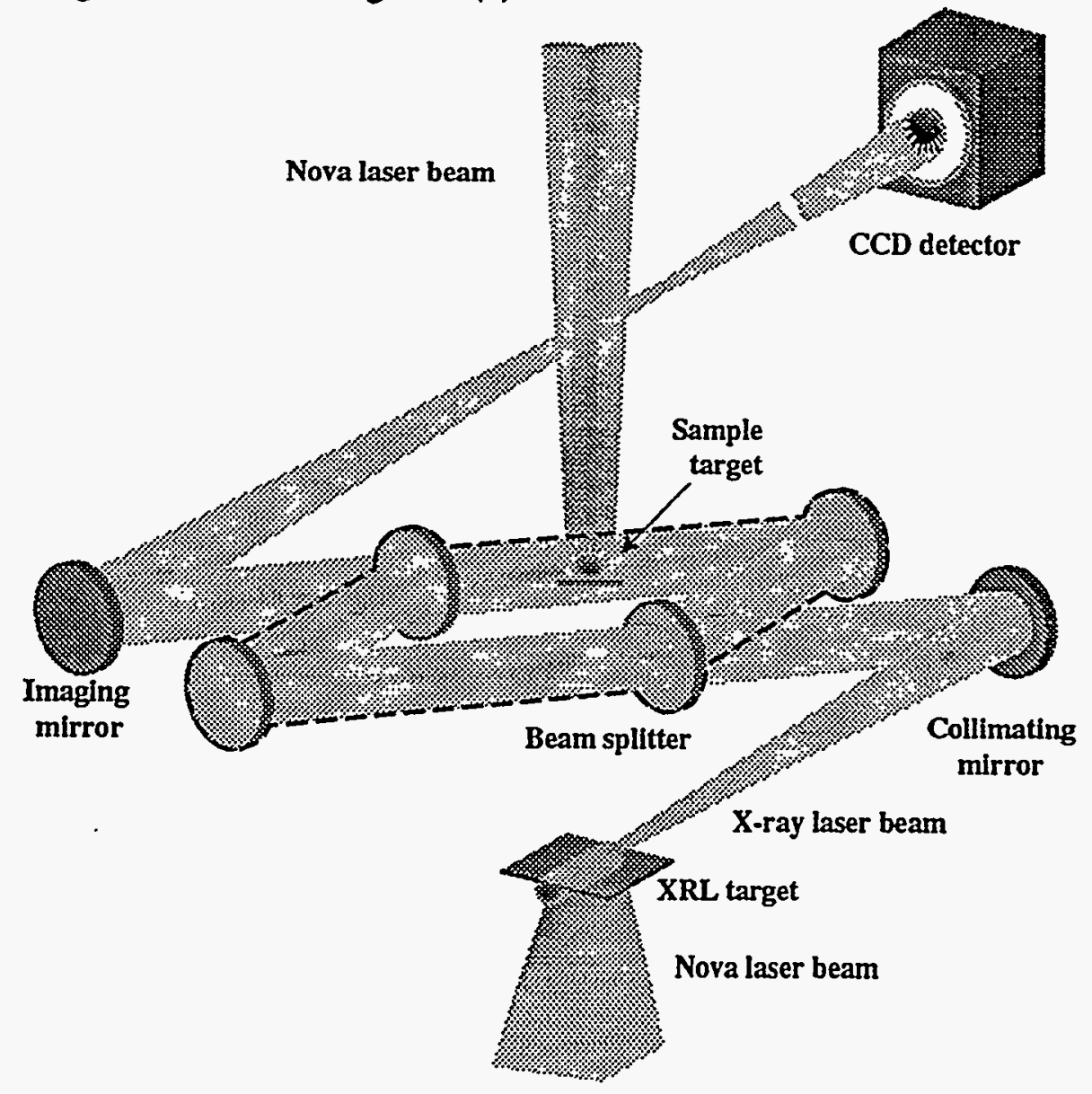

FIGURE 1. Experimental setup showing the optical components for probing transient plasma targets using a soft $x$-ray Mach-Zehnder interferometer. 
At $\mathrm{x}$-ray laser wavelengths this has only recently become possible because of the progress made in the fabrication of high quality beam-splitters (9). We use beam-splitters having a $1 \mathrm{~cm}$ square aperture and further having eight layer-pairs of Mo/Si on a $1000 \AA$ thick Si substrate. These splitters have a reflectivity of $\sim 25 \%$ and a transmission of $\sim 20 \%$. In the MachZehnder arrangement, the $\mathrm{x}$-ray laser beam is collected with a spherical multilayer mirror of $50 \mathrm{~cm}$ focal length. Mirror damage issues constrain each of the arms of the interferometer to have a total length of 1 meter.

In the Mach-Zehnder interferometer, the fringe visibility depends on both the spatial and temporal coherence of the $\mathrm{x}$-ray laser source. Because the temporal coherence length of the laser is only about $70 \mu \mathrm{m}$, it was necessary to prealign the interferometer with a white light source (10). Taking the temporal coherence (line width) requirements into account, one finds the factor of $10^{7}$ relative efficiency of the x-ray laser-interferometer to a $300 \mathrm{eV}$ blackbody backlighter. The number of fringe shifts seen at the CCD detector is $N_{\text {fringe }}=\delta \phi / 2 \pi=\left(1 / 2 n_{c r} \lambda\right) \int_{n_{e} d s}=n_{e} L / 2 n_{c r} \lambda$ where $L$ is the path length through the subject plasma. Returning to the issue of accessible regions of electron density and plasma scale length, we show in the shaded area of figure 2 the allowable parameters for hypothetical test plasmas with the characteristics of a neon-like selenium laser $\left(T_{e} \sim\right.$ $1000 \mathrm{eV},\langle\mathrm{Z}\rangle=30$ ).

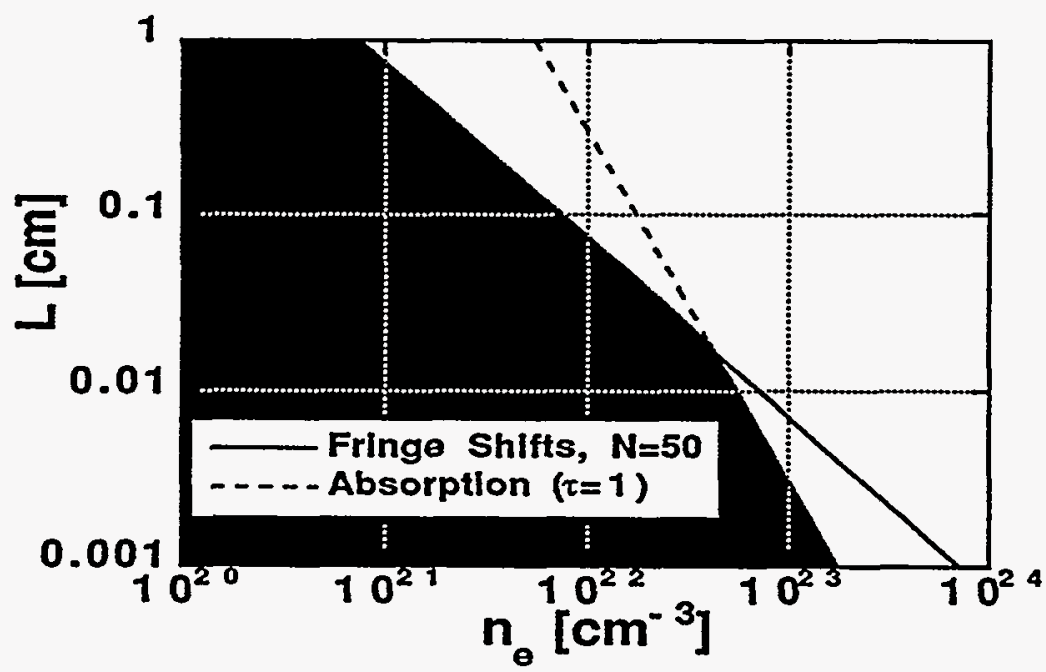

FIGURE 2 The shaded area is the parameter space accessible for plasma probing using a $155 \AA \quad x$-ray laser. The region is constrained by inverse Brehmstrahlung absorption and fringe visibility.

In the interferometer experiments we have done so far, two arms of the Nova laser were used, one to produce the backlighter yttrium laser, the other, appropriately timed, to produce the subject plasma (see figure 1). Figure 3 shows a sample interferogram. Here, the target was a triangular 
shaped mylar wedge irradiated from the top at $2.7 \times 10^{13} \mathrm{~W} / \mathrm{cm}^{2}$. The $\mathrm{CH}$ heating pulse was 1 ns duration and the $x$-ray laser drive pulse was $600 \mathrm{ps}$ resulting in an $\mathrm{x}$-ray laser snapshot of about $350 \mathrm{ps}$ duration beginning about $1.1 \mathrm{~ns}$ after the heating of the $\mathrm{CH}$ started. The fringe shifts give a sufficiently accurate measurement of the ablation electron density to test the different models of laser-plasma interaction in the radiationhydrodynamics code LASNEX $(11,12)$. We are presently proceeding to apply the interferometer to measure ablation in the interior of ICF hohlraums.

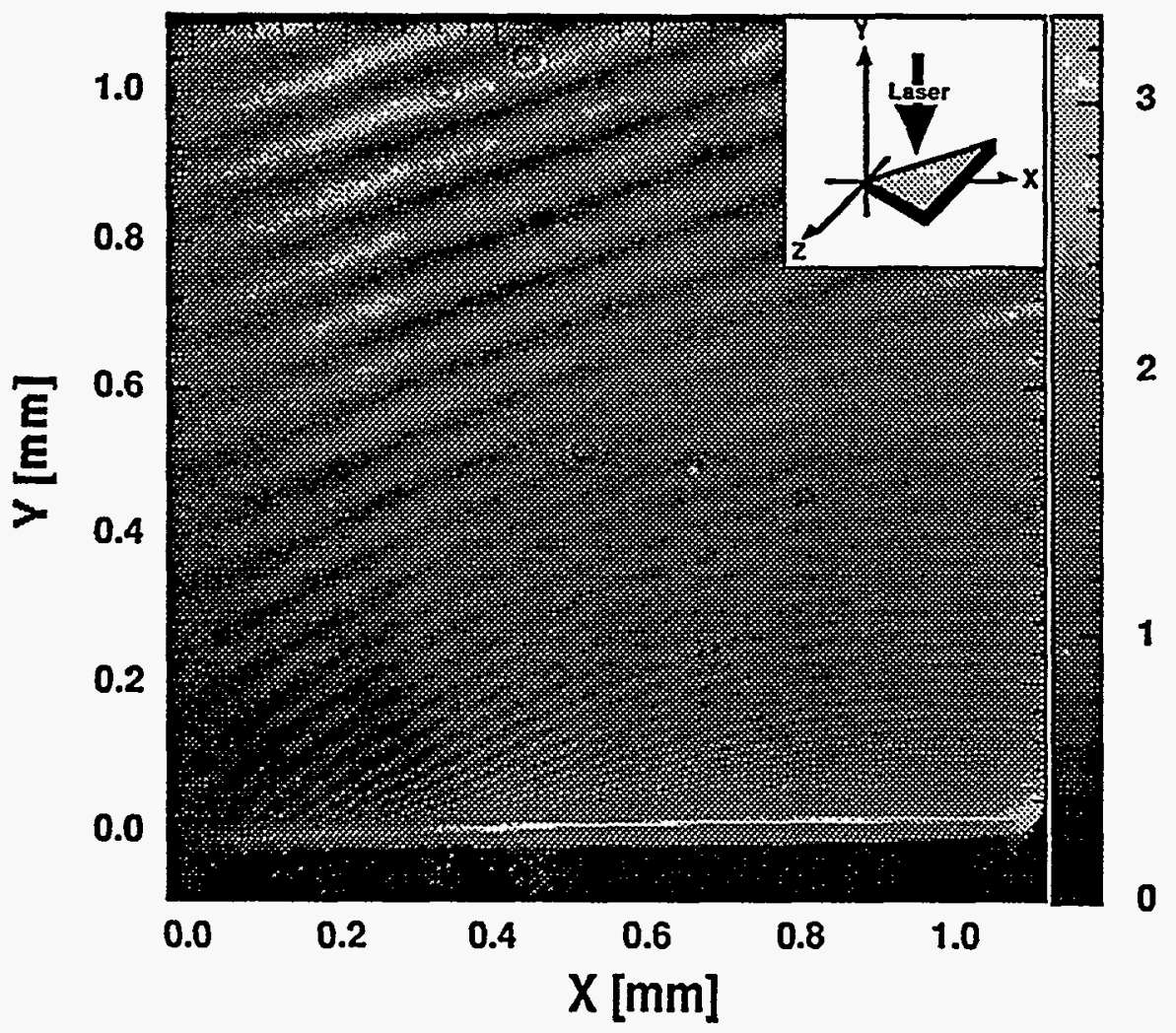

FIGURE 3. The interferogram of the plasma ablation from a $\mathrm{CH}$ wedge.

Two further experimental issues are clear from the results so far. One is the motional blurring that is evident in many of our 100-200 ps snapshots. Because of the difficulty in "gating" our CCD arrays faster than this, we are seeking methods to produce $\mathrm{x}$-ray lasers with pulses shorter than $20 \mathrm{ps}$ (for achieving imaging resolutions of less than $2 \mu \mathrm{m}$ at plasma expansions of $>10^{7} \mathrm{~cm} / \mathrm{sec}$ ). To achieve this we are developing a traveling wave method of exciting the laser (13). The second issue is the extraneous $\mathrm{x}$-ray fluorescence seen near the wedge surface. This is due to recombination lines that are within the interferometer bandpass of $8 \AA$. Ameliorating this will require a narrower bandpass. Clearly the laser line width itself could tolerate a much narrower bandpass.

Finally, a remark should be made about another application of the Mach-Zehnder interferometer. Since the fringe pattern is sensitive to the 
relative path length of the arms at the level of the temporal coherence length, the interferometer can be used in vacuum to measure the line shape of the x-ray laser, or for that matter, the line shape of a bright plasma source within the bandpass of the system. Thus, the interferometer can used as a Fourier transform spectrometer of very high accuracy (10):

In summary, the $x$-ray laser, coupled with new very efficient multilayer mirrors and beam-splitters, is proving to be a powerful probe of the physics of dense, transient plasmas. Work in progress will extend these initial results to detailed measurements of ICF hohlraum plasmas and to soft $\mathrm{x}$-ray Fourier transform spectroscopy.

\section{Acknowledgments}

This work was performed under the auspices of the U. S. Department of Energy by Lawrence Livermore National Laboratory under Contract No. W-7405-ENG-48. Part of this work was supported by the Institute Supporting Research Program at Lawrence Livermore National Laboratory.

\section{References}

1. Elton, R., X-Ray Lasers, New York, Academic Press, 1990.

2. MacGowan, B. J. , Da Silva, L. B.,Fields, D. J.,Keane, C. J.,Koch, J. A.,London, R. A., Matthews, D. L., Maxon, S.,Mrowka, S., Osterheld, A. L.,Scofield, J. H., Shimkaveg, G., Trebes, J. E., and Walling, R. S., Phys. Fluids B 4, 2326-2337, (1992).

3. Cauble, R., Da Silva, L. B., Barbee, T. W., Jr., Celliers, P., J. C. Moreno, A. S. Wan, Phys. Rev. Lett., 74, 3816, (1995).

4. Ress, D., Da Silva, L. B., London, R. A., Trebes, J. E., Mrowka, S., Procassini, R. J., Barbee T. W., Jr., and Lehr, D. E., Science, 265, 514, (1994).

5. Da Silva, L. B., Barbee, T. W., Jr., Cauble, R., Ciarlo, D., Celliers, P., London, R. A., Libby, S., Matthews, D. L., S. Mrowka, J. C. Moreno, D. Ress, J. E. Trebes, A. S. Wan, and F. Weber, Phys. Rev. Lett., 74, 3991, (1995).

6. Atwood, D. T., Sweeney, D. W., Auerbach, J. M., and Lee, P. H. Y., Phys. Rev. Lett., 40, 185, (1978).

7. Prasad, M. K., Estabrook, K. G. Harte, J. A., Craxton, R. S., Bosch, R. A., Busch, G. E., and Kollin, J. S., Phys. Fluids B 4, 1569, (1992).

8. Young, P.E., Phys. Fluids B 3, 2331, (1991).

9. Barbee, T. W., Jr., Rife, J.C., Hunter, W. R., Kowalski, M. P., Cruddace, R. G., and Seely,J. F., Appl. Opt., 32, 4852, (1993).

10. Celliers, P.,. Weber, F., Da Silva, L. B., Barbee, T. W., Jr., Cauble, R., Wan, A. S., and Moreno, J. C., submitted to Opt. Lett., (1995).

11. Zimmerman, G. B., and Kruer, W. L., Commun. Plasma Phys., 265, 514, (1994).

12. Wan, A. S., Da Silva, L. B., Barbee, T. W., Jr., Cauble, R., Celliers, P., London, R. A., Libby, S. B., J. C. Moreno, J. E. Trebes, and F. Weber, accepted for publication in JOSA $B,(1995)$.

13. Moreno, J. C., Nilsen, J., and Da Silva L. B., Opt. Comm., 110, 585, (1994). 